\title{
Chasing the Elusive Wrongdoing Intuition
}

\author{
DAVID WASSERMAN \\ Clinical Center Department of Bioethics \\ National Institutes of Health, USA
}

\begin{abstract}
In this paper, I offer a partial explanation of the tenacity of the wronging intuition in David Boonin's central non-identity case, Wilma. In Chapter 7 of The Non-Identity Problem and the Ethics of Future People, Boonin argues that the claims made against Wilma - that she wrongs someone or acts wrongfully without wronging anyone - are even less plausible than the "Implausible Conclusion" - that Wilma does nothing wrong. My arguments complement his, in explaining how the "Implausible Conclusion" is more plausible than it may appear. But some of the fault is Boonin's: the needlessly scant detail of Wilma provides a foothold for moral complaint. I will consider three ways in which Wilma's conduct, as described, could be regarded as wrongful. First, Wilma could be seen as breaching her duties as the steward of "the gift of life": her reasons for choosing to conceive a child now rather than in two months could be seen as slighting the beneficiary or devaluing the benefit. Second, shifting the focus from benefit to harm, Wilma could be seen as deviously evading her duty to protect her child from harm. Finally, Wilma could be seen as irrationally or impermissibly choosing more over less suffering. Whether or not these can be valid moral complaints, however, they apply to Wilma only if certain assumptions are made about her reasons for not delaying conception, assumptions permitted but not required by Boonin's description of the case.
\end{abstract}

Keywords: wronging, wrongdoing, procreative reasons, motivation, intuitions, insensitivity.

\section{INTRODUCTION}

On the second page of his comprehensive examination of the non-identity 
problem, The Non-Identity Problem and the Ethics of Future People, David Boonin presents an example of the direct version of the problem that he will refer to throughout the book. I will quote it at length, because it will be equally central to my largely sympathetic commentary (the ellipses replace passages that do not concern the type of the condition described or Wilma's decision):

"Wilma has decided to have a baby. She goes to the doctor for a checkup and the doctor tells her that there is some good news and some bad news. The bad news is that as things now stand, if Wilma conceives, her child will have a disability. The doctor cannot say precisely what the disability will be, but she can tell Wilma three things about it. First, it will be the kind of disability that clearly has a substantially negative impact on a person's quality of life ... Second ... this particular disability will clearly not be so serious as to render the child's life worse than no life at all. So while the disability will be considerably far from trivial, the child's life will nonetheless clearly be worth living. Finally, the disability will be irreversible. There will be no way to eliminate or mitigate its effects.

The good news is that Wilma can prevent this from happening. If she takes a tiny pill for two months before conceiving, her child will be perfectly healthy. The pill has no side effects and will be paid for by her insurance company. Fully understanding all the facts about the situation, Wilma decides that having to take a pill once a day for two months is a bit too inconvenient and so chooses to throw the pills away and conceive at once. As a result of this choice, her child [Pebbles] is born with a significant and irreversible disability."

Boonin stipulates that the "significant and irreversible disability" is blindness but invites readers to substitute another condition if they don't believe blindness fits the bill. I doubt it does, but I will accept the stipulation for purposes of my argument, which does not concern the impact of particular disabilities on quality of life but the central question Boonin addresses: does Wilma do anything wrong? Boonin denies that she does, defending the Implausible Conclusion, that Wilma's act of conceiving Pebbles is not morally wrong.

Unlike Boonin, I am not ready to acquit Wilma of wrongdoing, or of wronging Pebbles. My uncertainty persists despite agreeing with Boonin that a woman who chooses to conceive a child with a significant disability now, rather than a child without one in two months, need not wrong the child she ends up having, nor commit any other wrong. I also agree with Boonin that the leading arguments for Wilma's wronging Pebbles are mistaken, some obviously so. 
Part of the work in defending the Implausible Conclusion, however, lies in explaining the tenacity of the wrongdoing intuition, whose grip I have not fully broken. In invoking the Modesty Requirement against wrongdoing claims, Boonin is asserting that those claims have implications even less plausible than the Implausible Conclusion. The burden of proving immodesty can be reduced by showing the Implausible Conclusion to be more plausible than it may initially appear. Boonin seeks to do this in Chapter 7; again, I find little to disagree with there (although more than in Chapter 5). His strategy is to compare the case of Wilma and Pebbles (Wilma) to other cases of creating or extending worse-off lives. He claims that in these cases, the no-wrongdoing claim is plausible, and that if his arguments in preceding chapters have been successful, those cases are relevantly similar to Wilma. But I think he makes his task needlessly difficult by the way he describes his central case. Wilma is underspecified in several morally relevant respects; I will suggest that its scant details may pump the very intuition that Boonin devotes so much effort to undermining.

What do we know about Wilma's response to her doctor's news? She apparently accepts the pills initially, then discards them because she finds taking them "a bit too inconvenient." She seems to recognize that it is biologically impossible for any child conceived at least two months later to be the same-by standard identity criteria—as any child she could conceive now. ${ }^{1}$ That's all we know. We aren't told what she thinks about the prospect of having a blind child, though it's safe to assume she believes there is some reason not to. Otherwise, why bother taking the pills from the doctor? We can also assume that she takes her inconvenience as outweighing that reason, whatever it may be; this is not a case of akrasia or impulse. Can we flesh out her attitudes in a way that would warrant the claim that she wrongs Pebbles or (what may or may not be equivalent) commits a wrong involving Pebbles? I will suggest that we can.

There are certainly ways of fleshing out Wilma that preclude this claim; my point is emphatically not that Wilma necessarily wrongs Pebbles, but that she might be reasonably construed as having done so in the case as described. I will, so to speak, assess that case in the light most favorable to the prosecution. In Section 2, I will take an approach similar to Boonin's in Chapter 7 for a different, if not opposing, purpose: I will compare Wilma to cases in which in which a donor chooses whom to benefit for reasons that wrong, or at least slight, the beneficiary. I will argue that those cases are

1 As Melinda Roberts suggests in email correspondence, Wilma might have the same child if she could preserve the gametes for two months and then employ IVF, but to preserve an essential feature of the case (and avoid debates about necessary conditions for identity), I'll assume that any child so conceived would also be blind. 
relevantly similar to Wilma's, and that they suggest why she, too, might be regarded as slighting or wronging Pebbles in the case as described.

Of course, Wilma is just one of the standard hypotheticals used to illustrate the direct version of the non-identity problem, and it might seem that I have placed too much weight on its details-or lack of details. But Boonin adopts this case as his central example, which he refers back to throughout the book. It is also, as he notes, a slight variation on a case used by Derek Parfit (1984) to introduce the non-identity problem. Moreover, the resilient intuition that Wilma does something wrong may suggest that even if she can acquit herself of that charge, she has the burden of defending herself against the presumptive wrong. ${ }^{2}$

I will consider three ways in which Wilma's conduct, as described, could be regarded as wrongful or morally deficient. First, Wilma can be seen as breaching her duties as the steward of a distinctive kind of precious gift. Her reasons for choosing to conceive a child now rather than in two months can be seen as slighting the beneficiary or devaluing the benefit. Second, shifting the focus from benefit to harm, Wilma can be seen as deviously evading her duty to protect her child from harm, as Robert Noggle suggests in a recent article (Noggle, 2018). Finally, drawing on a suggestion made by Kieran Setiya, Wilma can be seen as irrationally or impermissibly choosing more over less suffering. Even if Wilma were guilty of any of these offenses, it would not account for the intuitive judgment that she does something as, or almost as, wrong, by having a blind child as she would by blinding an already existing fetus or child. But I'm convinced that this judgement is either deeply confused or (perhaps) worse, impersonally consequentialist.

The first claim of wrongdoing focuses on the good of the life that either Pebbles or Rocks would enjoy; it involves seeing Wilma, and prospective parents generally, as the stewards of a precious gift, one which the individual need not confer, but which can be conferred in ways that slight or disrespect the gift or its recipient. The second and third claim focus on harm rather than benefit: on the blindness that Pebbles experiences and that Wilma could have avoided by waiting to conceive. The second sees Wilma as acting wrongfully by creating an excuse for breaching her duty to protect her actual child from blindness - by rendering the fulfillment of that duty impossible. The third claim is that Wilma shows insensitivity to

2 This may suggest an asymmetry in direct nonidentity cases: that making a choice which leads to having a worse-off rather than a better-off child imposes a burden of justification to the resulting child that is not faced by a choice with the opposite result. Wilma as described does not clearly satisfy that burden, and while she could, it is not a burden she would face if she chose to wait. If a non-identity problem survives Boonin's sustained critique, it may lie in explaining this apparent asymmetry in the burden of justification. 
the harm of blindness in the way she responds to the prospect of that harm, choosing to subject her child to it for trivial, selfish reasons.

I doubt that Wilma acts wrongly in either of the first two ways and remain uncertain about the third. I will defend the more modest claim that if she does, it is only in virtue of the reasons for which she chooses to conceive now. This modesty reflects real uncertainty on my part about how to evaluate procreative or gestational decisions made without the "due diligence" and child-centered motivation that I believe all children brought into a harsh, dangerous world are owed. Despite this uncertainty, I am convinced that parents who bring children into being with such reflection and motivation commit no wrong whatsoever if they have a child they expect to be substantially less well-off that another they could have had - as long as they reasonably expect the child to have a good life, are committed to securing that outcome, and do not expect to significantly harm any third party.

I am also uncertain about another critical point: whether any wrong on the part of Wilma-as-described can be regarded as a wrong to Pebbles, giving her a complaint, or is rather a "victimless wrong," about which Pebbles has no special standing to complain. With reference to Boonin's overall argument, I will assume that Wilma's act harms no one, and that the case against her rests on the denial of one of two premises leading to the Implausible Conclusion: P4, "If an act does not harm anyone, then the act does not wrong anyone" or P5, "If an act does not wrong anyone, then the act is not morally wrong." The wrongdoing claims I will consider sometimes pose more of a challenge to P4, sometimes to P5. It is, however, not always easy to distinguish these challenges, a difficulty I will discuss in examining all three claims, especially the first. But I will argue that if Pebbles does have a complaint, contra P4, it is not one that the great value she finds in her life compels her to waive. That is because Wilma could have conceived her for reasons that would have given Pebbles no grounds for complaint.

\section{SLIGHTING THE RECIPIENT OR THE GIFT}

I In one of the earliest attempts to find a wrong in direct non-identity cases, Greg Kavka argued that it lay in the abuse of the progenitor's reproductive powers. He understood the wrong of such abuse in terms of a modified categorical imperative, that would "forbid treating rational beings or their creation ... as a means only" (110). Although his account has faced a great deal of criticism, there is a resilient appeal in the idea that the awesome 
power to create life comes with significant moral constraints-if not, or not only, the one Kavka identified. I want to explore the constraints on reproductive power that may be imposed by regarding prospective parents as the stewards of the "gift of life" they confer by conception and gestation. Of course, they are not stewards in any ordinary sense, because, at least on the prevailing view, they have no duty to confer the gift at all. Rather, they assume that role only if they decide to bear a child. And, of course, they do not give the gift of life to pre-existing recipients; that gift, so to speak, creates its own recipients.

In order to treat prospective parents this way, we must distinguish the gift from its recipient. In doing so, however, we may appear to treat the gift as "mere existence." We seem to strip the gift of its distinctive characteristics by treating it as something that can have different possible recipients. Although the life given is itself a particular, in the sense that that Pebbles and Rocks would receive different gifts, because they would have numerically different lives, those gifts would not differ qualitatively because they have no qualities beyond conscious existence.

But this view of the gift as bare existence is impoverished. Prospective parents, as opposed to sperm-donors, not only bring children into existence; they bring them into their lives, families, communities, and their time and place, making the gift they give much less generic. The setting for the child's life is not something distinct from the gift; a network of intimate relationships and a rearing environment are an integral (if severable and modifiable) part of it. At the same time, the character and value of the life given will obviously depend on its recipient. A life with the potential for rapturous experience and great achievement could not be given to a recipient with the potential for nothing more than mild euphoria and mediocrity. (Assessing potential is notoriously difficult, conceptually and empirically, but I leave those issues aside. $)^{3}$

3 These qualifications are critical if we are to frame the evaluation of Wilma's conduct in terms of the moral constraints on the donor of a precious gift. As I will discuss later, such donors can be regarded as indiscriminate or finicky in choosing the recipients. But it would be difficult to regard a donor as guilty of either excess when the value of the gift he appeared to under- or over-value varied substantially with the recipient. Similarly, it would be difficult to regard the donor as displaying an objectionable attitude toward a type of potential recipient if the type of potential recipient could only be identified in terms of the gift they could receive. For example, a female child might reasonably feel wronged by her parents if she learned that she had been gestated only because all of their male IVF embryos failed to implant. To regard her parents as having violated a moral constraint on the stewards of a precious gift-that they should not show sexual bias in bestowing it-it is necessary to regard the gift itself as gender-neutral, so to speak: the gift of life as a male is not one she could have received. (Perhaps "she" could have in the sense that a gamete or embryo with a Y chromosome could have been modified to have an X, which would be identity-preserving for non-essentialist about sex. But we can assume that was not a practical possibility in the case described.) 
If we can make sense of the notion of prospective parents as stewards of a precious gift, perhaps we can regard wrongful procreative decisions as violations of the duties imposed by stewardship. In some cases, the violation will slight only the gift, not the recipient; in others, it will give the recipient a complaint. In non-procreative contexts, the distinction is clear. If an art collector carelessly failed to appreciate the immense value of a painting, regarding it as a pleasant decoration, but gave it to her favorite nephew, it's not clear the nephew would have a complaint. A recipient need not be slighted in being given a gift that the donor mistakenly regards as a trifle, unless the donor regards him as worthy only of trifles. In contrast, a collector who appropriately valued the painting would slight the recipient if he gave it to a despised nephew, just to see what he would do with a work of art the collector believed he lacked the capacity to appreciate. (He might also slight the painting in this case by placing it in such philistine hands.)

Admittedly, it may sometimes be hard to tell if the donor slights the gift or the recipient. When one casts one's pearls before swine, one may be devaluing the pearls, the recipients, or both. The biblical injunction, taken literally, suggests the former, but the way in which the donor dispenses her pearls, say by casting them into manure for the recipients to root out, could slight the recipients as well, by treating them like swine.

What, then, are the moral constraints on the stewards of the precious gift of life, and can Wilma be said to violate any of them? And when does the violation of those constraints wrong the recipient, as well as, or as opposed to, the gift? Clearly, if there is a victim of the wrong, it must be Pebbles, at least if we take the conventional view, as I will, that merely possible people like Rocks have no standing to complain about the decisions, however flawed, that deny them actualization.

One place to start would be to treat a procreative steward, like a fiduciary, as obligated to act only in the interests he was charged to servefor the steward, the gift of life. A procreative steward would violate his duties if he chose how to dispose of the gift for which he was responsible on the basis of his personal convenience. It might be held that Wilma abused her stewardship by violating a duty not to choose the recipient of her gift on the basis of trivial, selfish reasons.

But this is far too demanding a standard for procreation. After all, some couples try to time pregnancy to spend the final months in the relative comfort of spring or fall, rather than the harsher temperatures of summer or winter. They do so recognizing, or able to recognize, that their timing is identity-affecting. They are permitted to time their pregnancies for their 
own convenience, as long as they are willing and able to care for the child conceived at the chosen time. In doing so, they do not devalue the precious gift they bestow.

In contrast, Parfit's 14-year-old girl, who has a child before she is ready to raise one, may fail to display adequate appreciation of the gift she is conferring. (I emphasize "may" because so much depends on the attitudes and beliefs she has in deciding to conceive.) She may also wrong the child, I would argue, by imposing an unacceptable risk that she would be unable to fulfill her responsibilities to it. ${ }^{4}$

It is less clear, however, that Wilma displays a similar failure to appreciate the immense value of the gift in choosing, for her own convenience, to bestow it on a blind rather than a sighted child. Although she presumably prefers a sighted child and believes it would have a better life, she hardly regards a blind child as an unworthy recipient, since she believes it would also have a good life and seems willing and able to raise it. Given these beliefs and attitudes, she would hardly display deficient appreciation for the gift in bestowing it on a blind child if she could not have a sighted one. Indeed, she would not value the gift appropriately if, after deciding to have a child, she changed her mind upon learning that she could only have a blind one. As I argue later, she would fail to recognize that the immense value of the gift to a sighted or blind child dwarfed any difference in its comparative value.

But even if Wilma need does not show a deficient appreciation of the gift, it might be thought that she slights Pebbles by the way she confers it on her, overriding a preference for another type of recipient for a reason as trivial as her temporary convenience. Of course, giving a benefit to a lesspreferred recipient need not slight the recipient. Someone offered a position after two more favored candidates had turned it down could have no complaint, even if he was hurt by the discovery. Getting a gift on the rebound does not itself seem to be a slight to anyone. In contrast, no one rejects Wilma's gift of life to a child she would conceive in two months; rather, she herself decides not to give the gift to a preferred recipient because of her own convenience. Pebbles might complain that if Wilma had really preferred a sighted child, she should not have overridden her preference for a trivial reason. But this seems a perverse complaint: the fact that Wilma did suggests that her preference against having a blind child was not very strong. And this seems to weaken, not strengthen, any claim of insult to Pebbles.

4 This claim raises questions, which I cannot address here, about when, or whether, one can violate the rights of a child who does not yet exist, and whose existence would not have been possible without a rights violation. 
There are cases in which overriding one's initial preference for recipienttype does seem to wrong the recipient, but these are cases in which the reasons for disfavoring the actual recipient are disrespectful, and where overriding them seems to add further insult. Thus, a Black diner would be wronged if he were admitted to a segregated restaurant that took down its "Whites Only" sign when exclusion became "a bit too inconvenient" because of slow business. In a procreative context, similar offense could be taken by a female child whose parents had strongly preferred a male child, and who had been gestated only after all the male embryos in the IVF array had failed to implant. But claiming that kind of wrongdoing by Wilma would only be plausible if her initial willingness to take the drug and delay conception was based on prejudice or aversion towards blind people, rather than on the belief-which, recall, I've accepted for the sake of argument - that a sighted child would have a much better life than a blind child. If Wilma would have had the same preference against having any kind of child expected to be significantly less well-off, regardless of the source of its hardships, it would be difficult to find bias. ${ }^{5}$ Wilma could only be faulted if, in deferring to her own convenience, she displayed a callous insensitivity to the suffering that accounted for this difference in expected well-being, a suggestion I consider in Section 4.

A final suggestion involves seeing the stewardship obligations of prospective parents in Aristotelian terms, as requiring them to avoid the extremes of indiscriminateness and finickyness in conferring precious gifts. This suggestion has some kinship to Rosalind Hursthouse's (1991) argument that abortion can be assessed in virtue-ethical terms, and that woman may reveal a kind of vice in aborting for reasons that reflect an insufficient appreciation of the value of human life or of parenthood. Unlike Husthouse's account, though, the approach I'm proposing seeks to find a wrong in the act (conceiving now), not, or not only, in a vice of the agent.

Prospective parents would arguably display indiscriminateness if they gave the gift of life to someone for whom they believed it would have only marginal value-someone whose life they expected to have so much pain or so little pleasure that it would barely be worth living. The steward of a precious gift should only give it to someone for whom it would be of significant value. To be willing to give the gift to anyone for whom it would not be bad, even someone who would have a life barely worth living, is to devalue it, to care too little for its robust appreciation. But Wilma does not even come close to that extreme: she expects Pebbles to have a life well

5 This wrongdoing claim was suggested, although not endorsed, by Melinda Roberts, email correspondence. 
worth living, well above any reasonable threshold for adequate enjoyment. Clearly, she would have devalued the gift if she regarded a blind child as barely capable of benefitting from it: it's not the actual value of the gift, but what she believes it to be, that is relevant in assessing her stewardship. But there's no indication she holds this dubious view. ${ }^{6}$

On the other hand, it would be both presumptuous and finicky to limit the gift of life to the recipient for whom it was expected to have the most value: presumptuous in assuming that one could make more than a rough guess about the comparative value of existence for different people; finicky because the value of the gift for many or most possible recipients would be great enough to dwarf the differences among them. To insist that the gift of life go to the candidate who can most enjoy it is to treat that gift in an inappropriate way, like a Stradivarius that should only be given to the most talented violinist. It is appropriate to be highly discriminating in bestowing an exquisitely crafted musical instrument to the most talented player because respect for the instrument requires a recipient who can fully exploit its musical potential. Moreover, a less talented violinist, even if he would have enjoyed playing it more than the prodigy who gets it, can get great enjoyment from a lesser instrument. The contrast with the gift of life is almost too obvious to spell out-nothing else can be enjoyed and only a noxious perfectionism would demand that life to the recipient who can achieve the most with it, or enjoy it the most. But there is no indication that Wilma's initial preference to delay conception to have a sighted child reflected any such finickyness or perfectionism.

Although in the end it is hard to justify, the impression that Wilma slights either Pebbles or the benefit she bestows by bearing her arises only because of the manner in which Wilma responds to her doctor's advice. No such impression would have arisen had she declined to delay conception, not because it was inconvenient, but because she was willing and able to raise a blind child. Her willingness need not have reflected the expectation that a blind child would have a life just as good as, or on a par with, that of a sighted child. It might have instead reflected the belief that even if the difference in well-being was substantial, it would be dwarfed by the goodness of either life, as well as the recognition that each child had "but one life to live." Wilma would not have slighted either the gift or the recipient in conceiving a blind child with such attitudes and expectations. Rather, she would have achieved a morally attractive mean between the extremes of indifference and finickyness.

$6 \quad$ It may also be the duty of prospective parents as stewards to carefully appraise that value, but that is a distinct issue. 


\section{DEVIOUSLY EVADING AN OBLIGATION}

Robert Noggle has recently offered an account of Wilma's wrongdoing as (primarily) victimless, which focuses on the harm of blindness, not the benefit of a rewarding life (Noggle, 2018). It begins with the claim that Wilma has a duty to protect her children from blindness and the recognition that in Pebbles' case, she is excused from fulfilling that duty by the impossibility of doing so. But she is not off the hook, since she has made it impossible to fulfill that duty: "[D] eliberately making it impossible to fulfill a moral obligation manifests a defective attitude toward morality an attitude which sees moral obligations as something to be dodged whenever they are inconvenient. ... [Acting] on this attitude is a wrongmaking feature that is independent of any wrong that might be done to Pebbles" (1). Noggle identifies Wilma's wrong as the violation of this Principle of Deliberate Impossibility (PDI), placing her in a rogue's gallery of duty-dodgers who make it impossible for them to fulfill an onerous duty.

Noggle's spells out his argument in four premises and a conclusion (8):

"1. Wilma is obligated to protect any actual child she has from blindness (Assumption).

2. It is morally wrong for Wilma to deliberately $U$ at tl, if Wilma expects her U-ing to make it impossible to $\mathrm{W}$ at t2, where Wilma's $\mathrm{W}$-ing at $\mathrm{t} 2$ would have been obligatory had Wilma's U-ing at tl not made it impossible for Wilma to $\mathrm{W}$ at $\mathrm{t} 2$, and the impossibility of her $\mathrm{W}$-ing is the direct cause of its being nonobligatory (PDI).

3. Wilma expects her forgoing the medicine and conceiving at tl to make it the case that, at $\mathrm{t} 2$, it is impossible for her to protect an actual child of hers from blindness.

4. Protecting this actual child from blindness would have been obligatory for Wilma at $\mathrm{t} 2$ if her act (at $\mathrm{t} 1$ ) of conceiving a child with incurable blindness had not made it impossible (and its impossibility is the direct cause of its being nonobligatory).

5. TTherefore, it is wrong for Wilma to deliberately forgo the medication and conceive Pebbles."

The weak link in Noggle's argument is Step 4. My bracketed insertions specify its application to Pebbles as well as Wilma:

"Protecting this actual child [Pebbles] from blindness would have been obligatory for Wilma at $\mathrm{t} 2$ [when she acquires responsibility for Pebbles' 
health and welfare] if her act of conceiving a child with incurable blindness had not made it impossible (and its impossibility is the direct cause of its being non-obligatory)".

The problem with this claim is that it's not the case that Wilma's act of conceiving Pebbles made it impossible for her to protect Pebbles from blindness, at $\mathrm{t} 1$ or $\mathrm{t} 2$, regardless of whether $\mathrm{t} 1 \mathrm{t}=\mathrm{t} 2$. It's not the case that had she not conceived Pebbles, it would have been obligatory for her to protect Pebbles from blindness, for the simple reason that there would have been no Pebbles to protect: it would have been impossible to protect Pebbles from blindness if she did not exist. It's true that if Wilma had not conceived an incurably blind child, but instead, say, the sighted Rocks, she would have been obligated to protect Rocks from blindness. But her actual child, per Step 1, is Pebbles, not Rocks. If Step 1 were modified with a definite description, like "her present and future children," then Noggle's argument would become just another version of the failed strategy of charging Wilma with violating a supposed de dicto duty to "her next child" - a strategy Boonin challenges in Chapter 2 of his book and which I address in the next section. Wilma could have fulfilled such a de dicto duty only by conceiving a different child than Pebbles, so it is hardly a duty whose breach would compel Wilma to offer an impossibility defense to the charge that she wronged her actual child Pebbles. It was never a duty she owed to Pebbles, and even if it somehow was, we can safely assume that Pebbles would have waived her right to its fulfillment.

Noggle also engages in a bit of questionable intuition pumping. The duty-evasions in the hypotheticals he presents to motivate PDI are objectionable in part because they involve harming or wronging third parties who exist independently of the duty evasion. Because Slippery Pete and Weaselly Willy (two of Noggle's duty evaders) have made themselves unable to take their turns teaching an 8:00 am course, the other faculty members have to do additional teaching. An independent wrong to third parties can also be found in the case of Clare, who, by developing the new elective course requested by her Chair, which makes it impossible for her to prevent this additional course from being taught by adjunct faculty in an exploitative arrangement. Clare thus contributes to, and is complicit it, the wrongful exploitation of adjunct faculty. There is no counterpart to this in Wilma's case - it's stipulated that no independently existing person suffers a harm or wrong as a result of her choice.

Finally, Noggle's application of PDI would require prospective parents to avoid having, or selecting against, very minor disabilities. If parents have a duty to protect their actual child against blindness, which they would deviously evade by having an incurably blind child, they also have a 
duty to protect their actual child from very minor impairments, which they would deviously evade by having a child with very minor incurable disabilities. But many or perhaps most of those who fault Wilma would not fault, even to a lesser degree, prospective parents who declined to select against very mild asthma or astigmatism. Indeed, they might fault as finicky a prospective parent who did select against such minor impairments. Yet they would condemn parents who, because it was a bit to inconvenient, declined to take easy precautions to prevent their actual child from becoming very mildly asthmatic or astigmatic. Parents do have a duty to protect their actual children from very minor disabilities, but they would not wrongfully evade that duty by having a child who could not exist without such a minor disability.

Even if Wilma could be said to have deviously evaded her duty to protect her child from blindness, that could hardly be said of a woman who declines to delay conception just because she was ready and able to raise a congenitally blind child. Indeed, she might find it far more inconvenient to have a blind child than to delay conception for two months and have a sighted child. She might be completely willing to accept that additional inconvenience, expecting that any child she has now will have a life well worth living and recognizing that it would not exist if she delayed pregnancy. She might welcome, and actively seek, a way to prevent or treat that child's blindness. She could conceive now while being committed to having prenatal surgery to prevent or treat blindness, were such surgery to become available during her pregnancy - even if that surgery would be far more burdensome than a two-month delay in conceiving. There is nothing devious in her intentions or attitudes; no duty that she is shirking. The appearance, which Noggle seeks to account for, that Wilma fails to take her duty as a prospective parent seriously, may reflect not her evasion of a parental duty to prevent her actual child's hardships, but rather her failure to show an appropriate concern for those hardships.

\section{DISPLAYING INSENSITIVITY}

Many people would likely judge that Wilma acted wrongly, and wronged Pebbles, just because she was indifferent about having a blind or sighted child. That indifference might be regarded as the source of the wrong to Pebbles. The focus of this claim, like Noggles', is on the harm to which Wilma would subject or expose Pebbles, however unavoidably. If, as I've been assuming, life would be much harder for a blind child than a sighted one, indifference between the two future lives displays insensitivity to the greater hardship. 
This complaint would seem even more plausible if Pebble's condition had a more clearly adverse impact on her well-being, e.g.., cystic fibrosis (CF) rather than blindness. The complaint would indict the mother for insensitivity to the substantial hardships of life with CF - the breathing difficulties, the disruption of activities, the increasing dependence on a difficult medical regimen, and, ultimately, premature death. The complaint does not assume that it would be wrong for a woman to have a child who lacked sight, or had CF, when she could, merely by waiting, have a different child who would have sight or not have CF. But it suggests that she must have a good reason for doing so.

In a paper published the year before The Non-Identity Problem and the Ethics of Future People, Kieran Setiya distills a complaint about insensitivity that is often made about hypothetical parents like Wilma:

"[T]he fact that your child will suffer as a result of your action is a reason against it and a reason to prefer the situation in which you wait. If you have a child later, she will suffer too - everyone does - but most likely she will suffer less. Since there is no other reason to have a child now, and no other relevant difference between these options, you should wait to have a child, if you have a child at all" (Setiya, 2014, 291).

Now . Wilma does have a reason for her choice - her own convenience - but Setiya likely means a good, moral, or appropriate, reason (earlier on the same page, he stipulates that you have no "urgent" reason.). Construing those terms in any plausible way, Wilma lacks such a reason. The question, however, in why she needs one for not waiting, but not for waiting, given that her choice will bring different children into existence. The answer Setiya gives abstracts the suffering from its bearer, and in doing so, echoes both de dicto and impersonal approaches to NIP.

The idea seems to be that just because Wilma could only apprehend any future child de dicto at the time she declined to select, she could only apprehend the harm to be selected against, and not the actual child who would bear it. Her refusal to delay conception could not be explained by her love or partiality for a particular child who would have a life worth living despite that harm. Given her epistemic and psychologicallimitations, Wilma's refusal to wait and thereby prevent the additional suffering can only be regarded as displaying insensitivity to it. The actual child wronged by that insensitivity has a complaint, even though she may be glad for the existence she could not have had without it.

I see this as the underlying logic of several recent arguments for wrongdoing. Perhaps the clearest example is Nicholas Vrousalis' (2013) 
claim that worse-off children whose existence results from a failure to screen are "smuggled into existence," with a parental attitude that is disrespectful because of its failure to show due concern for the child's harm. This logic has affinities to contractualist approaches like Rivka Weinberg's (2016), which seek to take existence "off the scales," and those, like Rahul Kumar's (2003), which maintain that the relevant principles concern types of people, not tokens. ${ }^{7}$ With existence off the scales, so is the distinct numerical identity of different future persons. All that's left is the simple choice between less and more suffering, about which it would be perverse to be indifferent. In much the same way, we could reasonably reject a principle that did not enjoin us to make our "future children" - a type - more rather than less happy.

I suspect that a similar logic lies behind the explanation prospective parents often give for their decision to select against disability: they do so for the welfare of "the child" because they want to prevent "their child" from having a harmful condition. These individuals are, at other moments, fully aware of the basic facts of reproductive biology, or of what Kavka (1982) called "the precariousness of existence." It is surely more charitable to assume that they find these facts of little or no relevance to their decisions than that they simply fail to grasp them. This is especially so when the distinct identities of the future children they could have are made salient by IVF selection. It hardly requires a high level of biological or philosophical literacy to recognize that a distinct child (or children) would develop from each embryo. But I doubt that the concern expressed about the welfare of "the child" is reduced much, if at all, by this recognition.

Clearly, Setiya himself recognizes that the child who suffers more would be a different person than the child who suffers less. His claim seems to be that this cannot supply an adequate reason for the woman to conceive now and bear the former. But this claim rests on an untenable assumption: that although the woman is, and knows she is, making a choice between two

7 Kumar seeks to find a wrong in Wilma's decision in its violation of a principle that no one, even Pebbles, could reasonably reject, given the level of generality at which it is framed. He argues that the appropriate principle will concern types of people, here parents and children. Such principles are familiar for other types, like drivers and pedestrians, types of which we can be tokens at different times. A principle prohibiting drunk driving could not be reasonably rejected, since it protects interests in life and limb over relatively trivial interests in convenience. In driving drunk, one puts pedestrians (as well as other drivers, passengers, etc.) - whoever they may be - at grave risk of injury. Kumar claim that by analogy, prospective parents put future children at risk by not avoiding the creation of children with additional burdens. But the analogy is flawed: while an act of drunk driving risks harm to particular individuals, even if they are now unknown, no one is subject to a risk of harm by a failure to prevent the creation of children with additional hardships, because that omission does not harm the child created. No possible harm, no risk. 
different children (or non-overlapping sets of possible children who can become actual), she can only apprehend each of the future children she is choosing among as a generic future child - a "bare subject of predicates" (to use Bernard Williams' memorable phrase, Williams, 1973) who will either have or lack additional suffering. This might be true of Wilma: from what we are told, she knows nothing about the future child she would have now or the one she would have in two months except that the former will be blind, the latter sighted, and so she seems to have no good reason to have a child who will "suffer" more. But this characterization rings false for many women who would decline to delay - a point I will return to shortly.

Setiya suggests the kind of position I'm attributing to him in another paper, where he presents a case, inspired by Caspar Hare (2013), involving a choice between equally-priced concert and theater tickets. If you think you'd enjoy the play as much as the music, it would be rational to prefer either one. It would still be rational if the price of one but not the other went up a dollar. Before the "sweetening" provided by the extra dollar, the reasons favoring the two performances were not strictly equal, merely on a par -- the reasons for favoring each one were incommensurable. ${ }^{8}$ Those reasons remain on a par even with the extra dollar. But if each ticket were held in an opaque box, with a dollar attached to only one, you should prefer that one. It's only when you can apprehend the alternatives as particulars - the concert and the play - that the extra dollar becomes what Frances Kamm (1987) has called "an irrelevant utility" (Setiya, 2019).

I suspect that something akin to this idea lies behind Setiya's claim about the two future children: they are like the opaque boxes, distinguishable only by the additional suffering that is attached to one. Given this profound limitation in how one can apprehend their lives, it would be immoral to select the life to which the additional suffering was attached. It would display an indifference or insensitivity to that suffering - the only discernable difference between the two lives. This might be a fair way to describe the way Wilma apprehends the lives of the children she chooses between. Although she expects that both would have good lives, those lives are opaque to her. But one of those lives comes with what Wilma herself regards as a significant harm - and that is the one she decides to have, for no good reason.

Moreover, since all prospective parents face these profound limitations in apprehending the particular lives their future children would lead, and

8 This incommensurability need not reflect anything as profound as "incommensurable values." The goodness of the two events, or artistic genres, differ in so many aesthetic respects that a full ranking is impossible. 
the particular individuals they would become, it might seem that any prospective parent who declined to delay conception to avoid blindness would, in the absence of a good reason, show similar insensitivity toward the (stipulated) harm of blindness, no matter how willing and able they were to raise a blind child. But this conclusion exaggerates the opacity of future lives to prospective parents. While it is obviously not possible for them to apprehend those lives in their full particularity, it is possible for them to see those lives as more than receptacles for differing amounts of well-being and suffering. This is in part because, as I argued in Section 2, prospective parents are not bestowing "mere existence"; they are, in normal circumstances, bestowing a life with a particular family in a particular place and time. They can anticipate in some detail - if not always accurately -- how the lives of a blind or sighted child would go, and how they would go differently.

Seen this way, the limitations faced by such prospective parents differ mainly in degree from those faced by the person choosing between the play and concert. Those performances are future events, which can be apprehended only by imagining and extrapolating. The prospective parents can apprehend some aspects of an uncertain future life; the box is, so to speak, translucent. Like the person choosing between the play and concert, they can envision the future, but only "through a glass, darkly." The person choosing a ticket can imagine the two performances; the prospective parent can imagine the lives of their possible children in the environment they expect to rear one or the other. Of course, their speculation could be far off the mark - the life of either child will be full of unpredictable developments. But the person choosing a ticket is also speculating, and his speculation could also be off the mark. The person making the choice may never have been exposed to either group or work; indeed, this could be the group's or the work's debut. Even if he is acquainted with both, the performance he experiences may fall far above or below his expectations. The prospective parent's choice thus may be more like that between the tickets than the opaque boxes holding the tickets. ${ }^{9}$

Seeing the life of a blind child this way would not involve judging it to be on a par with that of a sighted child - the analogy to the tickets does not go that far. Rather, it involves seeing the life of a blind child as rich and rewarding enough to make the difference in expect well-being morally irrelevant. Prospective parents need not regard the lives of a blind and

9 The difference is, admittedly, significantly greater in some of Hare's own cases, where the choice is between two fully accessible objects. But while those objects can be, in one sense, fully apprehended by the chooser, he must speculate to some extent about how the acquisition of one or the other will matter to him in the future. Perhaps the most dazzling one will lost its luster, while the plainer one will grow on her. 
sighted child as incommensurable in the same sense as the play and concert; they could regard blindness as a "bad difference" without regarding it as a reason for choosing one future child over another. ${ }^{10}$ They can apprehend the lives of their children as far more than mere existence with or without sight. Their understanding, however imperfect, of how their future child's blindness could be part of a life well worth living would suffice to rebut a charge of insensitivity.

The difference in expected goodness, while greater between the blind and sighted child than between the tickets with and without a dollar attached, may be even less relevant to the choice in the former case. If we raise the sum attached to a hundred dollars, it may become relevant - the two tickets may no longer be on a par, and it would no longer be rational to choose either. In contrast, the disutility "attached to" one child is already substantial, and the two lives are not on a par prudentially. But they do not need to be. What makes them incommensurable is not their expected wellbeing, but their separateness - a separateness that prospective parents are capable of appreciating more fully than Setiya acknowledges.

Thus, Peter Herissone-Kelly (2007) suggests that prospective parents should decide when to conceive or which embryo to implant by adopting an "internal perspective," on which they "imaginatively inhabit" the life of each future child to see if each, from its own perspective, would have acceptable prospects. If it would, then they have no moral reason to select another child with prospects judged better from an external perspective. From the perspective of the first child (or set of possible future children who could be conceived now), the fact that a different child conceived two months later would face less hardship hardly makes its own prospects less acceptable. If, as assumed, a blind child's life would have acceptable prospects, the internal perspective would give prospective parents no reason to disfavor such a child. The fact that they could have had a sighted child does not affect the blind child's prospects, or her retrospective appraisal of her own life.

It may appear that a stubborn asymmetry remains. Even if an imaginative exercise like that prescribed by Herissone-Kelly justifies a prospective parent in refusing to select against a worst-off child, no such exercise may seem necessary for a refusal to select against a better-off child. Wilma doesn't appear to owe Rocks a reason for waiting two months to conceive; alternatively, an adequate reason can be found in the mere

10 But given her knowledge of, and experience with, blindness or CF, would it be acceptable for her to base her decision on whether to have a child with those conditions on her preference for giving birth in fall rather than winter? I have conflicting intuitions, which I hope to explore in the future. 
fact that a child conceived after two months would not be blind. But perhaps that mere fact would not be enough for Rocks. If Wilma had been indifferent about whether she conceived a sighted or blind child, or even a child with or without $\mathrm{CF}$, and decided when to conceive solely only the basis of her comfort or convenience, she could also face a complaint of insensitivity from a sighted child, or a child without CF. The latter child, for example, could plausibly complain, “I'm relieved that I don't have CF, but it's little thanks to you. You didn't care if you had a child without or without $\mathrm{CF}$, and your only reason for having one without it was that you preferred a later birth!" His complaint would not be grounded merely in his mother's willingness to have a child with or without CF, but in the fact that her willingness reflected her lack of interest in, or concern about, the hardships of that condition. Had her willingness to have a child with or without CF arisen from the kind of exercise in $\mathrm{n}$ anticipatory empathy prescribed by Herissone-Kelly, he would have little or no ground for complaint. ${ }^{11}$

\section{CONCLUSION}

In Section 2, I suggested that prospective parents could be seen as the donors of a precious gift, required to choose the recipient responsibly, on pain of slighting the gift or the recipient. In Section 4, I suggested that prospective parents should not bring a child into existence without some sense of what their child's life would be like. Intentional but thoughtless conception, in contrast to merely accidental conception, may show a kind of disrespect for the future child - even if it does not result in, and does not even predict, any dereliction of parental duty. Although I doubted that Wilma could be seen as slighting either the gift or recipient, I found it plausible to claim that she displayed insensitivity to the (stipulated) hardship of blindness in choosing to have a blind child without seriously considering what life would be like for such a child. I also found that such insensitivity would give Pebbles, the blind child she ended up having, grounds for complaint.

11 If she had gone through that exercise, and judged the prospects of a life with or without CF or blindness to be acceptable, or if she had knowledge of, and experience with, CF or blindness, would it be permissible for her to base her decision on whether to have a child with those conditions on her personal preference for conceiving at a specific time of year? I have conflicting intuitions. Given the substantial differences in the lives of her possible children, and her life in raising them, there still seems something inappropriate about deciding which to conceive on the basis of her short-term comfort or convenience, rather than at random, or by "first come, first served." This is not to say that it would be wrong in any way for her to decide on the basis of substantial burdens or hardships she reasonably expected to face in raising one child or the other. 
But if Pebbles does have a complaint, the goodness of her life would give her no reason to waive it. Her grievance would not be about her blindness, which is an unavoidable aspect of a life she values. Rather, it would concern Wilma's failure to bring her into existence with, in my earlier phrase, due diligence. Unlike preventing the existence of a blind child, that moral exercise would not have required Wilma to delay conception, and there are no grounds for regarding it as identity-affecting (Roberts, 2007). The ex ante odds of Pebbles coming into existence would have been the same if Wilma had declined to delay for reasons consistent with due regard for the benefit she was conferring, adequate respect for its recipient, and keen appreciation of the expected hardships of the life she was creating. I think Boonin would be mistaken if he denied, as he appears to do in his Appendix on the rights waiver objection, that Pebbles had a moral reason to press her grievance about Wilma's failings in any of these respects. To adopt the language of Section 2, Pebbles could value the precious gift of her life while disapproving of the reasons for which the donor conferred it on her. Her disapproval would be compatible with her deep appreciation of the gift..

\section{BIBLIOGRAPHY}

Benatar, D. and Wasserman, D., 2015. Debating procreation: is it wrong to reproduce? New York: Oxford University Press, Ch. 8.

Boonin, D., 2014. The non-identity problem and the ethics of future people. New York, Oxford University Press, USA.

Hare, C., 2013. The limits of kindness. Oxford: Oxford University Press, Chs. 3, 4.

Herissone-Kelly, P., 2007. Parental love and the ethics of sex selection. Cambridge Quarterly of Healthcare Ethics, 16(3): 326-335.

Hursthouse, R., 1991. Virtue theory and abortion. Philosophy \& Public Affairs, : 223-246.

Kamm, F.M., 1987. The choice between people: "common sense morality and doctors. Bioethics, 1(3): 255-271.

Kavka, G.S., 1982. The paradox of future individuals. Philosophy \& Public Affairs, : 93-112.

Noggle R. 2019. Impossible obligations and the non-identity problem. Philosophical Studies, 176(9):2371-90.

Kumar, R., 2003. Who can be wronged? Philosophy \& Public Affairs, 31(2): 99-118.

Noggle, R., Impossible obligations and the non-identity problem. Philosophical Studies, 1-20. https://link.springer.com/article/10.1007/s11098-018-1130-7. Accessed July 5, 2018.

Parens, E. and Asch, A. eds., 2000. Prenatal testing and disability rights. Washington, DC: Georgetown University Press.

Parfit, D., 1984. Reasons and persons. OUP Oxford.

Roberts, M.A., 2007. The Non-identity fallacy: harm, probability and another look at Parfit's depletion example. Utilitas, 19(3): 267-311.

Setiya, K., 2018. Ignorance, beneficence, and rights. Journal of Moral Philosophy, published online, February 28, 2019, 1-19.

Setiya, K., 2014. The ethics of existence. Philosophical Perspectives, 28(1): 291-301. 
Vrousalis, N., 2013. Smuggled into existence: Nonconsequentialism, procreation, and wrongful disability. Ethical Theory and Moral Practice, 16(3): 589-604.

Weinberg, R., 2016. The risk of a lifetime: How, when, and why procreation may be permissible. Oxford University Press.

Williams, Bernard, 1973, The idea of equality, in: B. Williams, Problems of the Self, Cambridge: Cambridge University Press, pp. 230-249. 